\title{
Factors affecting Happiness of Expatriate Academicians and Expatriate Non-Academicians in Dubai.
}

\author{
Majid Wahid Shaikha, Kamarul Zaman bin Ahmadb* \\ aMBA student, Dubai Business School, University of Dubai, Dubai, United Arab Emirates, 0000000094@ud.ac.ae \\ ${ }^{b}$ Dubai Business School, University of Dubai, Dubai, United Arab Emirates, kbinahmad@ud.ac.ae \\ ${ }^{*}$ Corresponding author.
}

Received: 15 January 2018, revised: 14 March 2018, accepted: 14 March 2018 , published: 9 April 2018

\begin{abstract}
As no known research studied the determinants of happiness for academics and non-academics in Dubai Universities, the purpose of this paper is to determine the antecedents of happiness and compare academicians and non-academicians in selected Dubai Universities. It used a qualitative research design involving in-depth interviews followed by a quantitative study with cross-sectional surveys of academic staff and non-academic staff from different universities in Dubai. Results showed that there is no significant relationship between knowledge sharing and happiness of academics and well as non-academics. Happiness is significantly related to the other factors. Despite the small sample size of the academic group and that the study was targeted at the university staff in Dubai only, the findings of this research gives useful recommendations to Universities to improve happiness among their academic as well as non-academic staff. It will also provide recommendations for developmental purposes for the University of Dubai and the UAE's "Happiness and Positivity program."
\end{abstract}

Keywords: happiness, autonomy, knowledge sharing, work-family conflict, job satisfaction, life satisfaction, academics, Dubai.

\section{JEL codes:}

\section{INTRODUCTION}

The U.A.E has made the happiness of its citizens and residents its prime objective. The UAE's Prime Minister and Emir of Dubai, Sheik Mohammed bin Rashid Al Maktoum under the Smart Dubai Office, have undertaken a Happiness program aimed at fulfilling peoples everyday need, physical and intellectual (Smart Dubai, 2016). His Highness Mohammed bin Rashid Al Maktoum reported on Twitter that his new cabinet has Ohoud Al Roumi as its first "Minister of State for Happiness" (Remeithi, 2016). The main aim of incorporation of a Ministry of Happiness is to make Dubai the happiest city in the world (Remeithi, 2016). Currently, UAE is the $28^{\text {th }}$ happiest country in the world according to the World Happiness Report.

Many people are of the view that we do not need a formal definition of happiness - we know it when we feel it. We frequently utilize the term to portray an array of positive feelings, including delight, pride, satisfaction, and appreciation (Chan, 2005). We can also describe happiness as the "experience of joy, contentment, or positive well-being, combined with a sense that one's life is good, meaningful, and worthwhile" (Lyubomirsky, 2008).

Numerous studies have demonstrated that more happy people are more averse to becoming ill and have better odds of living longer. A study at the University of Warwick showed that happy people are more productive than their unhappy counterparts (Oswald, 2015). Research on happiness is increasing around the globe, and we can anticipate more and more insights and suggestions from researchers on how happiness can be achieved at every level of an institution, organization, and country. However, no research has compared the happiness of expatriate academicians with non-academics in Dubai. We aim to do this, and also provide recommendations for Universities in Dubai and the UAE's "Happiness and Positivity program." The research questions are: What are the factors that impact happiness? Are there any mediators of these relationships, such as job and life 
satisfaction? Are there any differences in the antecedents of happiness between academicians and nonacademicians?

\section{LITERATURE REVIEW}

\section{Happiness}

Researchers have found that there is no single formula to measure happiness. It is also not clear as to what are the determinants of happiness. The study of happiness is important because happier people contribute more towards the success of the organization and improves relationships at work (Jain, 2012). Many countries and institutions have begun to measure the level of happiness among their residents, and examine its associations with self-actualization, life fulfillment, achievement, and peacefulness in life. Probably the first attempt at measuring happiness at a national level was made by Bhutan, in their implementation of a Gross National Happiness (GNH) measure in 1972. The United Kingdom has recently declared that they will embrace a national study called a "Happiness Survey" with the ultimate goal of quantifying the level of happiness in their country (Helliwell, 2015). Various National Happiness programs are implemented in other regions like British Columbia, Brazil, and the United States (Pendery, 2014).

Psychologists say that a large portion of an individual's satisfaction level is attributed to hereditary, 10 percent influenced by outer conditions, and 40 percent influenced by convictions and practices that can be changed over a period (Lyubomirsky, 2008). In the professional workplace, happiness is a particular mood that motivates people to utilize their full capacity and work better. Individuals should be able to tackle the triumphs and challenges in their daily work if they are to achieve happiness at the workplace (Pryce-Jones, 2011). Healthy and happy people reflect positively in all the work they do, and people who can maintain a happy mood can keep their mind fit and increase their productivity levels and excel at their work (Seetubtim, 2016). On the contrary, workers who constantly feel tragic, nervous, demoralized, sad, and useless are unhappy. They may encounter problems in decision making and may also lose enthusiasm for work that once was pleasurable (Rashid, 2014). Previous research gives future directions as to what organizations can do to improve the overall happiness of academicians at work. Changes in extrinsic factors such as wage increases tend to have a temporary impact. However, when academicians are practicing their skills, building good relations, helping other people, the increases in the level of happiness levels accompanied by feelings of accomplishment can have lasting effects (Martin, 2011).

\section{Job Autonomy}

Job autonomy is the freedom and discretionary power present in the job to carry out various tasks (Brey, 1999). People with autonomy can control the pace of work and have discretion over work procedures. Job autonomy also impacts work strategies (Chung, 1977). Independence and autonomy are not the same as a person working with autonomy may need to rely on others, i.e., an autonomous person may not be independent if his/her work is interdependent with others (Chen, 2000). Job autonomy is often linked with high work effectiveness, and more elevated amounts of inborn motivation (Langfred \& Moye, 2004) since people think and view themselves as capable and innovative in achieving their work tasks (Saragih, 2011). Recently, job autonomy appeared to expand happiness and motivation of the employee, and it also results in a decreasing employee turnover rate (Robertson, 2016). According to Fischer (2011), autonomy is a superior indicator of happiness far better than income - money may give you autonomy but not necessarily happiness. Overwhelming demands from the job and little power over decision-making results in low levels of job satisfaction and high mental strain (Karasek Jr, 1979). In conclusion, job autonomy has a positive effect on employees' overall wellbeing, i.e., job, family, and life (Thompson, 2005).

\section{Hypothesis 1: Job autonomy is positively related to job satisfaction.}

Hypothesis 2: Job autonomy is positively related to life satisfaction.

\section{Hypothesis 3: Job autonomy is positively related to happiness.}




\section{Knowledge Sharing}

Knowledge Management is a topic of extensive discussions and research among human resource professionals and academicians (Ismail, 2005). Knowledge sharing between people is the procedure by which information held by an individual is changed over into knowledge that can be comprehended, ingested, and utilized by different people (Ipe, 2003). Knowledge sharing is the act of making information accessible to others within the organization and is considered to be one of the main functions of the work environment (Chakravarthy, 1999). The way of learning, working culture, willingness to share and take chances to share knowledge, play a very important part in improving the knowledge among academic staff in public universities (Sohail, 2009). To create and maintain a knowledge sharing culture in universities, the management should provide the employees with necessary tools and work environment which encourages knowledge sharing (Skaik, 2014). The Deans and Head of departments in universities should keep in mind intrinsic rewards when formulating reward policies (Jahani, 2011) as there is a positive relationship between knowledge sharing and rewards attached to it (Bartol, 2000). High levels of knowledge sharing in the workplace will probably result in higher job satisfaction and also higher performance (Trivellas, 2015). Knowledge sharing plays an essential role in the workplace because it not only advances successful business-related results, it also positively affects people's life satisfaction (Jiang, 2016). However, very little research has been done with regards to knowledge sharing in the UAE, compared with studies in the fields of construction, business, and management (Skaik, 2014). Furthermore, there is no study where knowledge sharing among academics and non-academicians in the UAE, about job satisfaction, life satisfaction, and happiness.

\section{Hypothesis 4: Knowledge Sharing is positively related to job satisfaction.}

Hypothesis 5: Knowledge Sharing is positively related to life satisfaction.

Hypothesis 6: Knowledge Sharing is positively related to happiness.

\section{Work-Family Conflict}

Many studies examined the negative impact of work on the family, i.e., work-family conflict. Work-family conflict alludes to clashing between the occupation and the family so that the gains attained in one is at the expense of the other (Greenhaus J. H., 1985). As such, work-family conflict arises when the needs and desires of one facet of life do not meet the needs and desires of the other (Greenhaus J. H., 2006). The conflict that occurs between one's work and family duties often results in forcing the individual to choose between the needs of the job or the needs of the family, when the two are mutually exclusive. Such conflicts result in low job satisfaction and low job performance (Byron, 2005). Academic work often requires focus and a huge amount of time and attention, to the detriment of the family (Christiana, 2013). Work-family conflict has a negative impact on subjective wellbeing (Lu, 2006), and many studies have found that there is a negative relationship between work-family conflict and life and job satisfaction (Ozeki, 1998).

\section{Hypothesis 7: Work-Family conflict is negatively related to job satisfaction.}

Hypothesis 8: Work-Family conflict is negatively related to life satisfaction.

Hypothesis 9: Work-Family conflict is negatively related to happiness.

\section{Job Satisfaction:}

Job satisfaction "is the positive emotional response to the job situation resulting from attaining what the employee wants from the job" (Kainth, 2011). Deficient pay rates, a high measure of stipends, workload, expenses relating to houses and automobiles are highly relevant variables for low job satisfaction of most academic individuals working in tertiary education Universities in Zimbabwe (Chimanikire, 2007). Results of previous research suggest that the lofty goals of higher education cannot be accomplished if there is low job satisfaction among academicians (Eyupoglu, 2009). The relationship between job satisfaction is unclear (Weaver, 1978) though some research suggests that individuals with a high level of job satisfaction also have 
high levels of happiness (Martínez-Martí, 2017). The conflicting results of previous studies indicate that the relationship between happiness and job satisfaction is still unclear and warrants further investigation.

Hypothesis 10: Job Satisfaction is positively related to Happiness.

\section{Life Satisfaction}

Life satisfaction has many definitions in the various literature. The term is ambiguous and difficult to study. Simply stated, however, life satisfaction can be regarded as the general evaluation of emotions and states of mind about one's life at a specific point in time. It is one of the three dimensions of prosperity (Diener, 1985). Life satisfaction is a complicated term and is in some cases used interchangeably with happiness, yet they are without a doubt two separate constructs (Chompoo, 2015). Many previous studies have investigated the various antecedents and outcomes of life satisfaction. For example, Linn (1985), examined life satisfaction of academic and clinical staff in association with job stress, work-family conflict, and job satisfaction. Various studies have had similar results whether life satisfaction or happiness is examined as the dependent variable $(\mathrm{Ng}, 1997)$. Happy people tend to be more satisfied in life, and their positive emotions increase life satisfaction (Cohn, 2009). This study investigates the relationship between life satisfaction and happiness among academics and nonacademics in Dubai.

Hypothesis 11: Life Satisfaction is positively related to Happiness.

Figure 1: Conceptual Framework

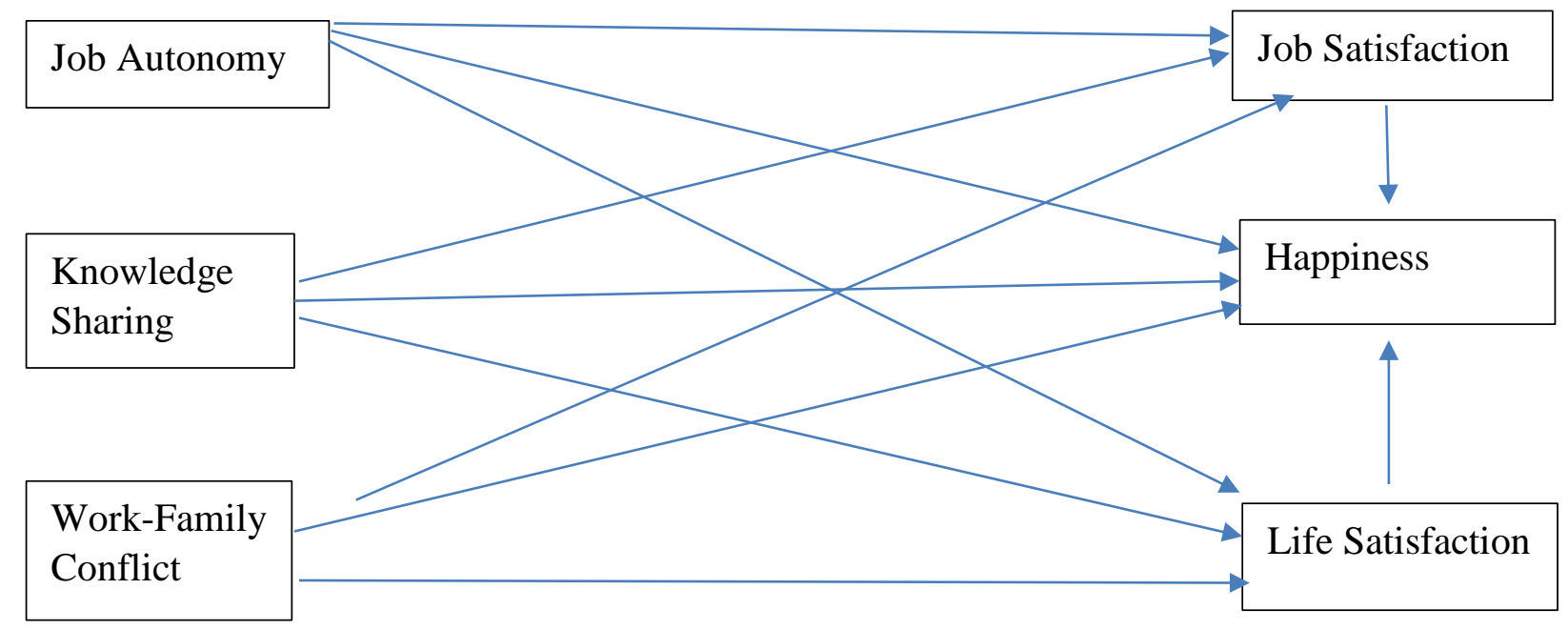

\section{Job Satisfaction and Life Satisfaction as mediators}

Figure 1 shows the relationships where job satisfaction and life satisfaction are dependent variables together with happiness. However, there are also arrows drawn from job satisfaction to happiness, and from life satisfaction to happiness. Thus, the model also treats job satisfaction and life satisfaction as mediators of the relationship between the independent variables of job autonomy, knowledge sharing and work-family conflict and the dependent variable of happiness. Accordingly, the hypotheses are:

Hypotheses 12: Job satisfaction mediates the relationship between the independent variables of job autonomy, knowledge sharing and work-family conflict and the dependent variable of happiness. 


\section{Hypotheses 13: Life satisfaction mediates the relationship between the independent variables of job autonomy, knowledge sharing and work-family conflict and the dependent variable of happiness.}

\section{METHODS}

We conducted in-depth, face-to-face interviews with ten expatriate teaching faculties at the University of Dubai. We started by asking a "standard question: "What makes you happy (or unhappy) at work?" Any other questions are follow up questions such as "What specifically" and "Can you elaborate on that" "What do you mean?" As this was an exploratory stage and not a purely qualitative research, the interview answers were not transcribed. Rather interview was semi-structured and concluded with a standard question, "Please list the top three factors that make you happy (or unhappy) at work." Respondents gave varying answers, and the top three factors that make them either happy or unhappy were deemed the critical factors affecting the happiness of academic personnel. The factors found related to happiness are job autonomy, knowledge sharing, and work-family conflict. These narrowed our choice from the myriad of other factors that could determine happiness. We also used the same factors to test whether they apply to non-academic staff. Based on the literature, we also included job satisfaction and life satisfaction as variables. So, following the interviews, cross-sectional surveys were used as a method to collect data from academic as well as non-academic staff from different universities in Dubai.

\section{Survey instrument development:}

Once the main factors affecting the happiness of academics were identified through the interviews, we developed a survey questionnaire, consisting of two sections. The first section covered demographics of the respondents (both academic and non-academic). The questions in this part included information about gender, age, industry, and their tenure.

The second section of the questionnaire consisted of different questions/items for each of the variables identified in the in-depth interview (mentioned in the subsequent paragraphs). A five-point Likert Scale was used to measure the variables with point 1 for (strongly disagree) and point 5 for (strongly agree). Only the variable happiness was measured on a seven-point scale, in line with the literature.

Job Autonomy was measured with a three item scale which was based on previous studies done by (Spreitzer, 2007) and the items in the scale are "I decide how I do my job", "I can decide on my own how to go about doing my work" and "I have opportunities for independence and freedom about how I do my job".

Knowledge Sharing was measured by a four-item scale, which was previously used by (Kanaan, 2013). The scale items are "I enjoy sharing my knowledge with colleagues," "I enjoy helping colleagues by sharing my knowledge," "It feels good to help someone by sharing my knowledge" and "Sharing my knowledge with colleagues is pleasurable."

The variable Job Satisfaction was measured by a five-item scale, which was previously used by (Judge, 1998). The scale included the following items "Most days I am enthusiastic about my work," "I feel fairly satisfied with my present job," "I find real enjoyment in my work," "Each day at work seems like it will never end" and "I consider my job rather unpleasant."

Work-Family Conflict was measured by a four-item scale, which was based on a previous study done by (Netemeyer, 1996 ). The scale items are "The demands of my work interfere with my home and family life", "The amount of time my job takes up makes it difficult to fulfil family responsibilities", "My job produces strain that makes it difficult to fulfil family duties" and "Because of my work-related duties, I don't have enough time for my family".

Life Satisfaction was measured by a five scale previously used by (Diener, 1985). The scale items are "In most ways my life is close to my ideal", "The conditions of my life are excellent", "I am satisfied with my life", "So far I have gotten the important things I want in life" and "If I could live my life over, I would change almost nothing".

Happiness is the only variable measured on a seven-point scale. The scale is based on the previous study by (Lyubomirsky S. \&., 1999). The scale included four items. The first item measures the happiness of the respondent in general. The second item of the scale measures the happiness of the respondents in comparison to their peers. The third item of the scale asks respondents to evaluate themselves whether they are happy in all situations. The fourth item of the scale asks the respondents to do the opposite, i.e., evaluate whether they are not happy in all situations. 


\section{ANALYSIS AND RESULTS}

\subsection{Panel summary and data description}

The purpose of the research is to find out the happiness levels of expatriate academicians in Dubai and to compare them with non-academicians working across Dubai. The research examines several demographics like age, gender, education, and experience of the respondents. The sample size for expatriate academicians is $n=70$, and the sample size for expatriate non-academicians is $n=145$. A total number of 41 males and 29 females participated from the academic sector, and 93 males and 52 females participated in the survey from the non-academic sector. The average years of experience for both the groups are 6.12 and 4.46 respectively. For the academic group, seven individuals worked for a government organization, and 21 and 42 worked for semi-government and private organization respectively. For the non-academic group, seven individuals worked for a government organization, and 12 and 126 worked for semi-government and private organization respectively.

Table 1: Demographics

\begin{tabular}{lll}
\hline Demographic value & Academic & Non-Academic \\
\hline Gender & 41 & \\
Male & 29 & 93 \\
Female & & 52 \\
Age & 1 & \\
$20-24$ & 2 & 39 \\
$25-29$ & 11 & 48 \\
$30-34$ & 18 & 21 \\
$35-39$ & 20 & 22 \\
$40-44$ & 17 & 10 \\
$45-50$ & 1 & 3 \\
$>50$ & & 2 \\
Organization Type & 7 & \\
Government & 21 & 7 \\
Semi-Government & 42 & 12 \\
Private Organization & & 126 \\
Organization Size & 34 & 103 \\
$>250$ employees & 36 & 42 \\
$<250$ employees & 6.12 & 4.46 \\
Mean years of Experience & &
\end{tabular}

The Cronbach alpha for all the factors of the data is found to be reliable and shown in Table 2. For example, the Cronbach alpha ( $\alpha$ ) for job autonomy is 0.912 in the academic group and 0.933 in the non-academic group. Table 2 gives all the readings for Cronbach alpha ( $\alpha$ ) for the all the factors in the data for both the groups academic and non-academic. All Cronbach alphas meet the minimum value of 0.7 specified by Nunnally (1978).

Table 2: Reliabilities Academic

\begin{tabular}{lll}
\hline Variable & Cronbach Alpha $\alpha$ & \\
\hline & Academic & Non-Academic \\
Job Autonomy & 0.912 & 0.933 \\
Knowledge Sharing & 0.794 & 0.968 \\
Work-Family Conflict & 0.933 & 0.968
\end{tabular}




\begin{tabular}{lll} 
Job Satisfaction & 0.807 & 0.875 \\
Life Satisfaction & 0.681 & 0.801 \\
Happiness & 0.859 & 0.758 \\
\hline
\end{tabular}

Table 3 and Table 4 show that the data exhibit convergent validity as all the factors from both the groups have composite reliability readings $>0.7$ and AVE (Average Variance Extracted) $>0.5$ as per the criterion developed by (Fornell \& Larcker, 1981).

Table 3: Reliabilities Non-academic

\begin{tabular}{lll}
\hline Variable & $\begin{array}{l}\text { Composite } \\
\text { Reliability }\end{array}$ & \\
\hline Job Autonomy & Academic & Non-Academic \\
Knowledge Sharing & 0.945 & 0.971 \\
Work-Family Conflict & 0.86 & 0.952 \\
Job Satisfaction & 0.952 & 0.976 \\
Life Satisfaction & 0.911 & 0.91 \\
Happiness & 0.904 & 0.883 \\
\hline
\end{tabular}

Table 4: Validity

\begin{tabular}{lll}
\hline Variable & AVE (AVERAGE VARIANCE EXTRACTED \\
\hline & Academic & Non-Academic \\
Job Autonomy & 0.85 & 0.918 \\
Knowledge Sharing & 0.608 & 0.832 \\
Work-Family Conflict & 0.833 & 0.912 \\
Job Satisfaction & 0.836 & 0.668 \\
Life Satisfaction & 0.613 & 0.717 \\
Happiness & 0.702 & 0.584 \\
\hline
\end{tabular}

Table 5: Correlations for Academics

\begin{tabular}{lllllll}
\hline & JATOT & KSTOT & JSTOT & WCTOT & LSTOT & HTOT \\
\hline JATOT & 1 & & & & & \\
KSTOT & $.33^{* *}$ & 1 & & & & \\
JSTOT & $.49^{* *}$ & $.35^{* *}$ & 1 & & & \\
WCTOT & $-.22^{*}$ & -0.1 & $-.37^{* *}$ & 1 & & \\
LSTOT & $.45^{* *}$ & $.47^{* *}$ & $.50^{* *}$ & $-.29^{* *}$ & 1 & \\
HTOT & $.22^{*}$ & 0.11 & $.55^{* *}$ & -0.08 & $.33^{* *}$ & 1 \\
\hline
\end{tabular}

${ }^{*}$ Correlation is significant at the 0.01 level (1-tailed).

${ }^{*}$ Correlation is significant at the 0.05 level (1-tailed).

$N=70$ 
Table 6: Correlations for Non- Academics

\begin{tabular}{lllllll}
\hline & JATOT & KSTOT & JSTOT & WCTOT & LSTOT & HTOT \\
\hline JATOT & & & & & & \\
KSTOT & $.40^{* *}$ & 1 & & & & \\
JSTOT & $.53^{* *}$ & $.46^{* *}$ & 1 & & & \\
WCTOT & 0.09 & -0.05 & -0.12 & 1 & & \\
LSTOT & $.44^{* *}$ & $.37^{* *}$ & $.43^{* *}$ & $-.22^{* *}$ & 1 & \\
HTOT & $.39^{* *}$ & 0.16 & $.34^{* *}$ & $-.22^{* *}$ & $.40^{* *}$ & 1 \\
\hline
\end{tabular}

${ }^{* *}$ Correlation is significant at the 0.01 level (2-tailed).

${ }^{*}$ Correlation is significant at the 0.05 level (1-tailed).

$N=145$

\subsection{Tests of hypotheses}

As per the Pearson's correlation table 5 and 6 findings:

$\mathrm{H} 1$ is supported and independent variable job autonomy is significantly related to job satisfaction where $\mathrm{r}=0.49$ $(p<0.01)$ in academic group and $r=0.53(p<0.01)$ in non-academic group. The correlation in both groups is almost similar.

$\mathrm{H} 2$ is supported and independent variable job autonomy is significantly related to life satisfaction where $\mathrm{r}=0.45$ $(p<0.01)$ for academic group and $r=0.44(p<0.01)$ in non-academic group. The correlation in both groups is almost similar.

$\mathrm{H} 3$ is supported, and independent variable job autonomy is significantly related to happiness where $r=0.22$ $(p<0.01)$ for the academic group and $r=0.39(p<0.01)$ in the non-academic group. The correlation is stronger in the non-academic group.

$\mathrm{H} 4$ is supported as independent variable knowledge sharing is significantly related to job satisfaction where $\mathrm{r}=$ $0.35(p<0.01)$ in the academic group and $r=0.46(p<0.01)$ in the non-academic group. The correlation is stronger in the non-academic group.

$\mathrm{H} 5$ is supported as independent variable knowledge sharing is significantly related to life satisfaction where $r=$ $0.47(p<0.01)$ in the academic group and $r=0.37(p<0.01)$ in the non-academic group. The correlation is stronger in the academic group.

$\mathrm{H} 6$ is not supported as independent variable knowledge sharing is not significantly related to happiness for both groups, where $r=0.11$ in the academic group and $r=0.16$ in the non-academic group.

$\mathrm{H} 7$ is partially supported as the independent variable work-family conflict is significantly and negatively related to job satisfaction where $r=-0.37(p<0.01)$ in the academic group and not significantly related in the nonacademic group where $r=-0.12(p>0.01)$. The correlation is strong in the academic group but very weak in the non-academic group.

$\mathrm{H} 8$ is supported as independent variable work-family conflict is negatively related to life satisfaction where $r=-$ $0.29(p<0.01)$ in academic group and $r=-0.22(p<0.01)$ in non-academic group. The strength of the correlations in both groups is similar.

$\mathrm{H} 9$ is partially supported as the independent variable work-family conflict is not related to happiness in the academic group where $r=-0.08$ and is negatively related in non-academic group where $r=-0.22$. The correlation is significant in the non-academic group but insignificant in the academic group.

$\mathrm{H} 10$ is supported as job satisfaction is significantly related to happiness where $r=0.55(p<0.01)$ in academic group and $r=0.34(p<0.01)$ in non-academic group. The correlation is stronger in the academic group compared to the non-academic group. 
$\mathrm{H} 11$ is supported as life satisfaction is significantly related to happiness where $r=0.33(p<0.01)$ in academic group and $r=0.40(p<0.01)$ in non-academic group. The correlation is stronger in the non-academic group compared to the academic group.

\subsection{Tests of mediating effects}

To the test the mediating effects we relied on the process and conditions laid out by Kenny (1986). According to Baron \& Kenny (1986), the first condition required is that the independent variable must be significantly correlated with the dependent variable before any analysis regarding mediators can be carried out. Referring to Table 5, when only the academic respondents are taken into account, the independent variables of knowledge sharing and work-family conflict are not significantly correlated with happiness. Only the dependent variable of job autonomy is significant. Since we treat these independent variables as a group, mediator analyses are not conducted for the respondents who are academics. So, the following tests of mediation are done with nonacademics only.

Looking at Table 6 (i.e., non-academics) job autonomy and work-family conflict are significantly related to happiness. However, knowledge sharing is not significantly related to happiness. Since two out of three relationships are significant here, tests of mediating effects of job and life satisfaction are conducted concerning the independent variables of job autonomy and work-family conflict. The b value of the relationship between job autonomy and happiness is .31 significant at the 0.01 level. When job satisfaction was introduced into the equation, the correlation between job autonomy and happiness drops to .23. However, because the $b$ value of .23 is still significant, we conclude that there is a partial (as opposed to a full) mediating effect of job satisfaction among non-academics.

The $b$ value of the relationship between work-family conflict and happiness is -.12 significant at the 0.01 level. When job satisfaction was introduced into the equation, the correlation between work-family conflict and happiness drops to -.104 (minus sign ignored) and significant at the 0.05 level. However, because the $b$ value of -.104 is still significant at the 0.05 level, we conclude that there is a partial (as opposed to a full) mediating effect of job satisfaction among non-academics. In short, partial support for H12 was obtained.

The $b$ value of the relationship between job autonomy and happiness is .31 significant at the 0.01 level. When life satisfaction was introduced into the equation, the correlation between job autonomy and happiness drops to .21 but still significant. We conclude that there is a partial mediating effect of life satisfaction on the relationship between job autonomy and happiness among non-academics.

The $b$ value of the relationship between work-family conflict and happiness is -.12 significant at the 0.01 level. When job satisfaction was introduced into the equation, the correlation between work-family conflict and happiness drops to -.08 (minus sign ignored) and not significant! We conclude that there is a full mediating effect of life satisfaction on the relationship between work-family conflict and happiness among non-academics. In short partial support for $\mathrm{H} 13$ was obtained.

\section{CONCLUSIONS}

This research supports previous research in that job autonomy is significantly related to job satisfaction and life satisfaction. This is true for both academics and non-academics, and the strength of the relationships are somewhat similar. However, it is interesting to note that the relationship between autonomy and happiness is stronger for the non-academic group, compared with the academic group. The results are surprising as one would think that the relationship would be stronger for the academic group since the results of the semistructured interview with academics uncovered autonomy as one of the top three factors affecting happiness. Perhaps further studies are needed to investigate why this is so.

Knowledge sharing is also significantly related to job satisfaction. Again, the relationship is stronger in the nonacademic group compared with the academic group, contrary to expectations. We expected this because the results of the semi-structured interview with academics uncovered autonomy and one of the top three factors affecting happiness, so we expected it to be particularly strong among academics (even though we did not interview non-academics). On the other hand, the relationship between knowledge sharing and life satisfaction 
is stronger in the academic group. This does not come as a surprise, and there is a common belief that academics love to share knowledge, and when able to do so, they become satisfied with life. However, knowledge sharing is not significantly related to happiness for both groups. One possible reason is that happiness is a wide construct encompassing work and non-work aspects, whereas job satisfaction is more specific to work.

Interesting results are found relating to $\mathrm{H} 7$, in that work-family conflict is significantly related to job satisfaction for the academic group and not significant for the non-academic groups. Perhaps, academics are more affected by any imbalances in work-family conflict due to unmet expectations, resulting in lower job satisfaction. The jobs of academics in some universities in Dubai are fairly rigid and with long hours, with faculty having to sign attendance forms and be present in their offices during workdays as well as some weekends, in contrast with many other universities around the world, where they have more flexiblility in scheduling their working hours. Thus, for the sample of academics in this study, work-family conflict results in lower job satisfaction. Work-family conflict is negatively related to life satisfaction, and this affects both academics and non- academics to a similar degree. On the other hand, work-family conflict is not significantly related to happiness for the academic group but is significantly negatively related to happiness in the non-academic group. One possible reason is the small sample size of academics (seventy) compared with non-academics (a hundred and forty-five). There might be a significant negative relationship between work-family conflict and happiness for academics if we collected a larger sample.

Job satisfaction is related to happiness for both groups, although the relationship is much stronger for academic groups than non-academic groups. Possibly academics probably attach more importance to work, and to be satisfied with work means to be happy. On the other hand, non-academics seem to be less dependent on job satisfaction to make them happy. Finally, life satisfaction is related to happiness, for both academics and nonacademics. The relationship is only slightly stronger for non-academic group compared with academics, but they are significant for both.

We conducted tests for mediating effects of job and life satisfaction for only the non-academic group because the relationship between the independent variables of knowledge sharing and work-family conflict are not significantly correlated with happiness in the academic group. For the non-academic respondents, job satisfaction was a partial mediator of the relationship between autonomy and happiness, and between workfamily conflict and happiness. Life satisfaction was a partial mediator of the relationship between autonomy and happiness, and a full mediator between work-family conflict and happiness. The full mediation occurred possibly because the independent variable was the conflict between the work and family, and the mediator examined was satisfaction with life as a whole (which incorporates the dimension of work and outside of work). In other words, work-family conflict impacts life satisfaction, which in turn impacts happiness. It is pertinent to remind readers that these mediating relationships of job and life satisfaction were obtained with non-academic respondents only.

The present research mainly contributes to the literature and our understanding of the relationship between Happiness and other factors like job satisfaction, job autonomy and life satisfaction in the context of expatriate academicians and non-academicians working in Dubai. In relation to the UAE's "Happiness and Positivity program," the findings of this research suggest that to increase happiness levels of an individual, the government or employers should try to increase the levels of other factors like job satisfaction, job autonomy, and life satisfaction for they can improve happiness significantly.

A surprising finding and one which we argue is a particular strength of this research is the finding that knowledge sharing is not significantly related to happiness for both academics as well as non-academics. This means that expatriate academicians are no different from non-academics in this respect. A possible reason could be that expatriate academics (like non-academics) work in Dubai because of the extrinsic and financial rewards rather than intrinsic rewards such as knowledge sharing.

\section{LIMITATIONS AND FUTURE RESEARCH}

In spite of the contributions this research provides, the research has a few limitations. Firstly, the sample size for the expatriate academic group is relatively small. Arguably, the relationships between all the independent variables and happiness could be found with a larger sample of academics, and this would also mean that mediating tests could be done with the academic group. Thus, a larger sample of academicians will improve the accuracy of the research findings. Secondly, the research is targeted towards academicians in the city of Dubai only - a place often associated with the pursuit of wealth and materialism, and the same may not be true for 
other parts of the world. A worldwide study is warranted as it would give a more detailed picture of the relationships and their contingencies.

\section{REFERENCES}

Akpofure, R. R. (2006). Job satisfaction among educators in colleges of education in Southern Nigeria. Journal of Applied Sciences, 1094-1098.

Baron, R., \& Kenny, D. (1986). The moderator-mediator variable distinction in social psychological research: Conceptual, strategic, and statistical considerations. Journal of Personality and Social Psychology, 1173-1182.

Bartol, K. a. (2000). Incentives and motivation. In: Compensation in organizations: Progress and prospects. S. Rynes \& B. Gerhardt (Eds.), 104-147.

Brey, P. (1999). Worker autonomy and the drama of digital networks in organizations. . Journal of Business Ethics, 15-25.

Byron, K. (2005). A meta-analytical review of work-family conflict and its antecedents. Journal of Vocational Behaviour, 169198.

Chakravarthy, B. Z. (1999). Knowledge sharing in organizations: A field study. St. Paul: University of Minnesota, Strategic Management Resource Center.

Chan, G. M. (2005). Happiness in University Education . International Review of Economics Education, 20-45.

Chen, J. R.-H. (2000). Faculty autonomy: Perspectives from Taiwan. Higher Education, 203-216.

Chimanikire, P. M. (2007). Factors affecting job satisfaction among academic professionals in tertiary institutions in Zimbabwe. African Journal of Business Management.

Chompoo. (2015, June 6). Life-satisfaction and Its 7 Contributors - Positive Psychology Program. Retrieved from Positivepsychologyprogram.com: https://positivepsychologyprogram.com/life-satisfaction/

Christiana, O. O. (2013). Work-Family role conflict among academic women in Nigerian Public Universities. International Academic Conference Proceedings. Osun State, Nigeria.

Chung, K. H. (1977). Motivational theories and practices. . Grid.

Cohn, M. A. (2009). Happiness unpacked: positive emotions increase life satisfaction by building resilience. Emotion, 361.

Diener, E. E. ( 1985). The Satisfaction with Life Scale. Journal of Personality Assessment, 49, 71-75.

Duong, M.-Q. (2013). The Effects of Demographic and Institutional Characteristics on Job Satisfaction of University Faculty in Vietnam. International Journal of Academic Research in Progressive Education and Development, 78-92.

Eyupoglu, S. Z. (2009). The relationship between job satisfaction and academic rank: a study of academicians in Northern Cyprus. Procedia-Social and Behavioral Sciences, 686-691.

Fischer, R. a. (2011). What is more important for national well-being: money or autonomy? A meta-analysis of well-being, burnout, and anxiety across 63 societies. Journal of personality and social psychology, 164.

Fornell, C., \& Larcker, D. (1981). Structural equation models with unobservable variables and measurement error: Algebra and statistics. Journal of marketing research, 382-388.

GNH. (2017, February 10). Centre for Bhutan Studies and GNH. Retrieved from http://www.bhutanstudies.org.bt/: http://www.grossnationalhappiness.com/articles/

Greenhaus, J. H. (1985). Sources of conflict between work and family roles. Academy of management review, 76-88.

Greenhaus, J. H. (2006). Health consequences of work-family conflict: The dark side of the work-family interface. In Employee health, coping and methodologies. Emerald Group Publishing Limited, 61-98.

Ipe, M. (2003). Knowledge sharing in organizations: A conceptual framework. Human resource development review, 337359.

Ismail, M. a. ( 2005). Implication of knowledge management (KM) in higher learning institutions. International Conference on Knowledge Management. Kuala Lumpur: PWTC.

Jahani, S. T. (2011). Is reward system and leadership important in knowledge sharing among academics. American Journal of Economics and Business Administration, 87-94.

Jain, R. (2012). Employee job happiness quotient in the realm of RSMML. Indian Journal of" Applied Research, 104-107.

Jiang, Z. a. (2016). Knowledge sharing and life satisfaction: The roles of colleague relationships and gender. Social Indicators Research, 379-394.

John F. Helliwell, R. L. (2015). World Happiness Report. Newyork: Sustainable Development Solutions Network.

Judge, T. A. (1998). Dispositional effects on job and life satisfaction: The role of core evaluations.Journal of Applied Psychology, 83,17-34.

Kainth, G. S. (2011). Job Satisfaction: A Challenging Area of Research in Education. 
Kanaan, R. \&. (2013). The impact of knowledge sharing enablers on knowledge sharing capability: An empirical study on Jordanian telecommunication firms. European Scientific Journal, ESJ, 9(22).

Karasek Jr, R. A. (1979). Job demands, job decision latitude, and mental strain: Implications for job redesign. . Administrative science quarterly, 285-308.

Langfred, C. W., \& Moye, N. A. (2004). Effects of task autonomy on performance: an extended model considering motivational, informational, and structural mechanisms. Journal of applied psychology, 934.

Linn, L. S. (1985). Health status, job satisfaction, job stress, and life satisfaction among academic and clinical faculty. Jama, 2775-2782.

Lu, L. G. (2006). A cross-cultural study of work/family demands, work/family conflict, and wellbeing: the Taiwanese vs. British. Career Development International, 9-27.

Lyubomirsky, S. \&. (1999). A measure of subjective happiness: Preliminary reliability and construct validation. Social Indicators Research, 46, 137-155.

Lyubomirsky, S. (2008). The how of happiness: A scientific approach to getting the life you want. Penguin.

Martin, B. (2011). 'On being a happy academic.' Australian Universities' Review, pp. 50-56.

Martínez-Martí, M. L. (2017). The Relationship Between Orientations to Happiness and Job Satisfaction One Year Later in a Representative Sample of Employees in Switzerland. Journal of Happiness Studies, 1-15.

Netemeyer, R. G. (1996). Development and validation of work-family conflict and family-work conflict scales. Journal of Applied Psychology, 81: 400-410.

$\mathrm{Ng}$, Y. K. (1997). A case for happiness, cardinalism, and interpersonal comparability. . The Economic Journal, 1848-1858.

Oswald, A. J. (2015). Happiness and productivity. . Journal of Labor Economics, 789-822.

Ozeki, E. E. (1998). Work-family conflict, policies, and the job-life satisfaction relationship: A review and directions for organizational behavior-human resources research. Journal of applied psychology, 139-149.

Pendery, D. R. (2014). The Taiwanese Student Happiness Initiative: Fulfilling Lives and Success in the Future. . Journal of Social Change, 6(1).

Pryce-Jones, J. (2011). Happiness at work: Maximizing your psychological capital for success. . John Wiley \& Sons.

Rashid Aziz, S. M. (2014). Personality and happiness among academicians in Malaysia. . Procedia-Social and Behavioral Sciences, 4209-4212.

Remeithi, N. A. (2016, March 23). "UAE Minister Aims To Maintain Happiness Established By Leaders 2016. Web. 9 June 2016. Retrieved from The National: http://www.thenational.ae/

Robertson, T. (2016). Retrieved from http://work.chron.com: http://work.chron.com/effects-autonomy-job-satisfaction14677.html

Saragih, S. (2011). The Effects of Job Autonomy on Work Outcomes: Self Efficacy as an Intervening Variable. International Research Journal of Business Studies, 203-215.

Seetubtim, M. (2016, July 2). "Why You Should Focus on Happiness, Not Productivity",. Retrieved from www.huffingtonpost.com: http://www.huffingtonpost.com/mo-seetubtim/why-you-should-focus-on-h_b_7703896.html

Skaik, H. \&. (2014). Determinants of Knowledge Sharing Behaviour among Academics in United Arab Emirates. International Journal Of Knowledge And Systems Science, 54-70.

Smart Dubai. (2016, May). Retrieved from www.smartdubai.ae: http://www.smartdubai.ae/story060202.php

Sohail, M. S. (2009). Knowledge sharing in higher education institutions: Perspectives from Malaysia. Vine, 125-142.

Spreitzer, G. (2007). Taking stock: A review of more than twenty years of research on empowerment at work. In C. Cooper \& J. Barling (Eds.), The handbook of organizational behaviour. Thousand Oaks, CA.: Sage Publications.

Thompson, C. A. (2005). Relationships Among Organizational Family Support, Job Autonomy, Perceived Control, and Employee Well-Being. Journal of Occupational Health Psychology, p100-118. 19p.

Trivellas, P. A. (2015). The impact of knowledge sharing culture on job satisfaction in accounting firms. The mediating effect of general competencies. Procedia Economics and Finance, 238-247.

Weaver, C. (1978). Job satisfaction as a component of happiness among males and females. Personnel Psychology, 831 840. 